BLS 33, No 1 2007. DOI: http://dx.doi.org/10.3765/bls.v33i1.3524

(published by the Berkeley Linguistics Society and the Linguistic Society of America)

\title{
Interpreting Intra-Regional Southern Vowel Distinctions
}

\author{
VALERIE FRIDLAND \\ University of Nevada, Reno
}

Recognizing that linguistically and socially meaningful speech is formed within locally defined and constructed communities, recent research has highlighted the importance of pushing beyond descriptive accounts of local speech to a fuller understanding of the perceptions and attitudes behind speakers' linguistic realizations. Gaining insight into fundamental questions involving the origin, diffusion and meaning of sound changes requires integrating examination of what speakers do productively, what they hear perceptually and what they believe attitudinally.

Many studies have sought to record or examine the types of phonological, morpho-syntactic and lexical differences that separate Southern dialects from others nationally, resulting in a number of very good descriptive studies about the features used in various Southern locales. Still, research on such varieties and their speakers is only beginning to examine how complex ideological positioning regionally interacts with and determines the use of non-standard Southern features. Rarely have studies synthesized descriptive work with perception studies and attitudinal surveys drawn simultaneously from the same population to provide a more comprehensive look at language use and language choices.

Adding more layers of complexity to our understanding of speech in the modern South is the fact that many Southern dialects are currently being affected by a series of vowel shifts known collectively as the Southern Vowel Shift, or SVS. In this shift, often characterized as a chain shift, the long tense front vowels lower and centralize, while the short lax front vowels raise and peripheralize. This 'reversal' so to speak results in a system that is acoustically very different from that found elsewhere in the U.S., leading to discussion about growing divergence across U.S. regional vowel systems. However, there is also another set of vowel shifts affecting vowels in the South in which the high back vowels are fronting acoustically, or being realized farther forward in the mouth. These changes, though, are not unique to the South and are in fact found in every major U.S. dialect region. Thus, vowels may not be leading us as far apart regionally as we might at first believe. What has become clear is that speech in the modern South is changing in ways that both bring it closer to and further away from speech 


\section{Valerie Fridland}

elsewhere in the U.S. This begs the question of how such changes might reflect ideological shifts in Southern and national self-identification.

My work in Memphis, Tennessee over the past seven years attempted to examine the nature of speech in that region, both productively in terms of the actual acoustic position of the Southern vowel system and perceptually, in terms of how local speakers view these regional differences, particularly in terms of competence and solidarity measures. This paper attempts to characterize some elements from this work that bear on what life-long Southerners living in Memphis, TN believe about their own speech and that spoken around them and how they reconcile their competing membership in both local and larger speech communities.

Production samples taken in the late 1990s established that Memphians did indeed show evidence of a number of aspects of the Southern Vowel Shift (Fridland 2001, 2006). While the high front vowels did not show a true reversal of the tense and lax tokens, they were often overlapping and well defined in acoustic space. The mid front vowels, on the other hand, were completely reversed acoustically in almost every speaker, Black and White, analyzed from the Memphis area. Similarly, all speakers showed extensive fronting of the high back vowel classes, suggesting that back vowel fronting was quite active in local speech.

If, as it appears to be, Southern speech is being affected by specifically local (Southern) shifts AND at the same time non-localized global shifts such as back vowel fronting, a natural question, it would seem, is what role are these changes serving for Memphians? Are they serving a sociolinguistic or purely linguistic purpose? Since back vowel fronting is so widespread, found not only among most American dialects but in many other languages as well and seems to be accounted for by fairly uniform and natural processes (drift), it seems an unlikely candidate for social marking. Changes to the front vowels, on the other hand, are much more localized, with the different U.S. regions showing strikingly different acoustic positioning for these vowels. Thus, my research attempted to explore whether speakers perceived these shifts positively or negatively and whether these impressions changed depending on the nature of shift involved, namely local or global.

Using vowel tokens synthesized to show various degrees of Southern shifting for the front vowels and various degrees of fronting for the back vowels, a twopart perception test was designed to probe these questions (Fridland, Bartlett and Kreuz 2004, 2005). In one part of the study, participants were asked to rate vowel tokens (played individually in monosyllabic word contexts) on scales from 1-3 measuring the perceived level of education and pleasantness of the speaker. In general, listeners rated more Southern shifted tokens less educated and less pleasant than tokens which had not been shifted toward Southern norms, as indicated in Table 1 below. 
Interpreting Intra-regional Southern Vowel Distinctions

Table 1: Education and pleasantness mean ratings by vowel sub-system (Front vowels vs. back vowels) on a 1 (worst) - 3 (best) scale.

\begin{tabular}{|l|l|l|}
\hline & Education & Pleasantness \\
\hline SVS shifted Front vowels & 1.67 & 1.72 \\
\hline Non-Shifted Front vowels & 1.86 & 1.77 \\
\hline Fronted Back vowels & 2.11 & 1.89 \\
\hline Non-fronted Back vowels & 2.14 & 1.99 \\
\hline
\end{tabular}

In terms of whether listeners showed any differences in awareness of local shifts compared to global shifts, Memphians found that SVS shifted front vowels were less educated and less pleasant sounding than fronted or non-fronted back vowels. While this could suggest that it is not local shifts that are salient on such scales, but global shifts which socially are more highly regarded, this is an unlikely interpretation. In another part of the study asking the same participants to pick out the most 'Southern' sounding vowels when played two tokens synthesized for different degrees of shift, back vowel shift differences were not very salient as Southern markers, with most participants scoring around chance when selecting between fronted and non-fronted back vowel tokens. However, they were much better at recognizing Southern shifted front vowels as more 'Southern' sounding. Thus, it is the Southern shifted front vowels, not the fronted (or peripheral) back vowels that apparently are being noticed by participants as more familiar in terms of local speech. Thus, since shifted front vowels are more salient to listeners in this regard, it is likely it is this 'Southern association' which is pulling down competence and solidarity ratings for Southern shifted front vowel tokens, not any prestige associated with back vowels more generally. Instead, back vowel fronting seems to have crept into the Southern vowel system essentially unnoticed and unmarked for localness, education or pleasantness scales. Front vowels, on the other hand clearly are recognized as local variants. This Southern uniqueness subsequently seems to create a negative context within which these variants are viewed on education and pleasantness. Variants recognized as more Southern are perceived as less educated and less pleasant than those without Southern associations.

Such linguistic insecurity, perhaps, is not unusual among groups whose varieties have long been the subject of extreme comment and ridicule. But, the fact is that Southern speakers continue to use these variants in their speech and clearly see these variants as locally identifying. However, this type of task specifically drew speakers' attention to specific linguistic items rather than their more general perceptions of local speech. So, in some way, Memphians' broader sociolinguistic identity must be mediated by intra-Southern affiliations and local pride, which outweigh some of the negative beliefs they hold about their own speech. 


\section{Valerie Fridland}

This lead to the question of what types of folk linguistic beliefs surround Southerners and how these stereotypes have become part of their own discourse. Unfortunately, you do not need to look very hard to discover the kinds of images that are routinely drawn about the South, nor is it surprising that such portrayals are notorious within the Tennessee or larger Southern community. In fact, an article in a Tennessee based newspaper, The Tennessean, ran with the headline "Southern stereotypes prove tough to shed: Region's past is sometimes all that rest of nation sees (Tennessean.com 1/2/2002)". The text discusses the common and endearing images of the South as backward, ignorant and racist, particularly by those living outside the region.

How are such negative portrayals of the South deflected by those who live there? Clearly, negative stereotypes about the inhabitants of the South abound and locals are certainly not impervious to these images. What is particularly interesting though are the different tactics Southerners use to try and fight these unflattering representations. In several cases, locals tried to point out the positive attributes of their states or attempted to provide facts about their community that disputed those more widely believed. In other words, they try to defend themselves in the face of these stereotypes by disputing that they carry any widespread validity. More interesting, though, was the second strategy that was often adopted, that of redirecting the negative stereotypes to other areas of the South that they see as responsible for the images. Both approaches are exemplified in the following quote from Mark Potok, director of the Southern Poverty Law Centers Intelligence project, which appeared in an online article:

\footnotetext{
"People think that the Klan and white supremacist groups in general are Southern artifacts, but that simply is not the truth....We see as many hate groups, and certainly as many hate crimes, in Northern and even coastal states." But even Mr. Potok couldn't help taking a fun jab at Mississippi: "Over here in Alabama, we say, 'Thank God for Mississippi' or else we'd be last in everything (Bookerrising.com 2006)."
}

Similarly, in the article cited above that ran in The Tennessean, Mississippi is mentioned several times as a state that has a particularly bad rap in a quote appearing from local author John Egerton:

"A movie like Mississippi Burning sticks in people's minds.... The FBI was virtuous and the law enforcement of Mississippi were evil... There's enough truth in all of that to convince some people that everybody must be that way (Tennessean.com 1/2/2002)."

Further shedding light on the question of how modern Southerners view themselves are the results of a study performed by University of North Carolina sociologist Larry Griffin (2003) which suggested that fewer and fewer Southerners self-identify as Southern. In his research based on poll data, Griffin found that Southerners from every ethnic, gender and age group were less likely to selfidentify as Southerners than they were a decade before. He attributes this decline 


\section{Interpreting Intra-regional Southern Vowel Distinctions}

to two predominant factors: one, the core 'Southern identifying' constituency of the South is being dispersed due to migration and increased national rather than local identity and two, the images associated with being Southern are less positively perceived than in years past while national consciousness is being heightened due to the threat of terrorism and war. Similarly, research by Reed et al. (1990) comparing the number of entries for 'Southern' vs. 'American' named businesses in the South as reported in the local yellow pages showed a similar attrition. In peripheral areas of the South, this ratio has shown a declining number of 'Southern' identifying listings with a corresponding increase in 'American' or 'National' listings. Like Griffin, the authors believe these results suggest greater national identification at the expense of local Southern identification.

My research question was how this competing local and national identity is reconciled for Memphians when evaluating the speech around them on correctness and pleasantness scales. To approach this question, Memphians were given the folk dialectology task designed by Dennis Preston $(1986,1989,1993)$ in which they were asked to rate speech in all fifty states on correctness, pleasantness and degree of difference scales. While regional contrasts are widely discussed in such folk dialectology work, intra-regional ratings are not as often explored. This aspect of the research, therefore, was primarily interested in examining how Memphians viewed themselves linguistically compared to other states within their region, particularly in light of the widespread stereotypes surrounding the region. Table 2 shows Memphians' ratings for Southern states, going from states with the lowest scores to those with highest scores on all three surveyed dimensions. 


\section{Valerie Fridland}

Table 2: Memphians' mean ratings for each state within the South on three constructs, ordered from lowest (0) to highest scores (9) in the folk dialectology study.

\begin{tabular}{|c|c|c|c|c|c|}
\hline \multicolumn{2}{|c|}{ Correctness (0-9) } & \multicolumn{2}{|c|}{ Pleasantness (0-9) } & \multicolumn{2}{|c|}{ Difference (0-3) } \\
\hline State order & & State order & & State order & \\
\hline Mississippi & $m=2.68$ & Arkansas & $\mathrm{m}=3.85$ & Tennessee & $\mathrm{m}=.54$ \\
\hline Arkansas & $\mathrm{m}=2.77$ & Alabama & $\mathrm{m}=3.93$ & Arkansas & $\mathrm{m}=.99$ \\
\hline Alabama & $\mathrm{m}=2.85$ & Mississippi & $\mathrm{m}=4.04$ & Mississippi & $\mathrm{m}=.86$ \\
\hline Louisiana & $\mathrm{m}=3.10$ & Louisiana & $\mathrm{m}=4.61$ & Georgia & $\mathrm{m}=1.10$ \\
\hline Kentucky & $\mathrm{m}=3.87$ & Oklahoma & $\mathrm{m}=4.70$ & Alabama & $\mathrm{m}=1.15$ \\
\hline Texas & $\mathrm{m}=3.93$ & Kentucky & $\mathrm{m}=4.74$ & Kentucky & $\mathrm{m}=1.16$ \\
\hline Georgia & $\mathrm{m}=4.11$ & Texas & $\mathrm{m}=4.93$ & Texas & $\mathrm{m}=1.31$ \\
\hline Tennessee & $\mathrm{m}=4.25$ & W. Virginia & $\mathrm{m}=5.26$ & So. Carolina & $\mathrm{m}=1.51$ \\
\hline Oklahoma & $\mathrm{m}=4.63$ & So. Carolina & $\mathrm{m}=5.27$ & No. Carolina & $\mathrm{m}=1.55$ \\
\hline So. Carolina & $\mathrm{m}=4.71$ & Georgia & $\mathrm{m}=5.40$ & Florida & $\mathrm{m}=1.56$ \\
\hline Florida & $\mathrm{m}=5.07$ & No.Carolina & $\mathrm{m}=5.47$ & Louisiana & $\mathrm{m}=1.67$ \\
\hline No.Carolina & $\mathrm{m}=5.11$ & Tennessee & $\mathrm{m}=5.50$ & Oklahoma & $\mathrm{m}=1.67$ \\
\hline W. Virginia & $\mathrm{m}=5.27$ & Virginia & $\mathrm{m}=5.58$ & W. Virginia & $\mathrm{m}=1.83$ \\
\hline Virginia & $\mathrm{m}=5.61$ & Florida & $\mathrm{m}=5.62$ & Virginia & $\mathrm{m}=1.83$ \\
\hline $\mathrm{DC}$ & $\mathrm{m}=6.64$ & $\mathrm{DC}$ & $\mathrm{m}=5.90$ & $\mathrm{DC}$ & $\mathrm{m}=2.23$ \\
\hline
\end{tabular}

Compared to other regional constructs, Memphians did find the Southern region significantly less correct than the other larger U.S. regions, the North and the West $(\mathrm{F}(1,179)=229.967, \mathrm{p}<.001$ and $\mathrm{F}(1,179)=194.875, \mathrm{p}<.001$, respectively) on the map rating task. Given what we know about how non-Southerners tend to view the South, it is not so surprising that Memphians have been affected by these negative stereotypes. However, if we examine the intra-Southern ratings a little bit more closely (Table 2), we will find that perhaps Memphians do not buy into such stereotypes wholesale. Instead, they seem to draw some very interesting intra-Southern distinctions, with some Southern states faring much better than others on both correctness and pleasantness scales. The two most salient areas for Memphians seem to be the more Southwestern states of Mississippi, Arkansas, Alabama and Louisiana, which Memphians view as least correct and least pleasant, and the coastal Southeastern states including the Virginias, the Carolinas and Georgia, which they view as quite correct and generally more pleasant. Florida and D.C. are also viewed high on correctness and pleasantness ratings, though these states are less 'Southern' in population and therefore may be getting a ratings boost from being relatively indefinable regionally. Tennessee, where Memphis is located, is less tainted than some of the other Southern states, although most of the coastal states do much better than the raters' own home state.

So, what differences among these focal Southern areas are Memphians tuning into and what does this intra-regional division suggest about Memphians own 


\section{Interpreting Intra-regional Southern Vowel Distinctions}

self-image? First, it is interesting to explore the states Memphians see as least correct more carefully. Part of these state's downgrading may simply be related to one key factor: location, location, location. All four of these 'core incorrect' states are, along with Tennessee, located in the Mississippi River Delta, and, in fact, MS and AR (the two lowest rated states in both categories) sit directly on the border with Memphis.

Memphis is located in the southwest most (and lowest) corner of Tennessee and it is commonly referred to as the 'Tri-state' area, since there is a great deal of in and out flow between Shelby county (containing the Memphis area) and DeSoto and Crittenden counties (containing the MS and AR border areas, respectively). In fact, $85 \%$ of Shelby county's in and out migration was to other adjacent local counties in the 1990's according to Census data. Thus, these three states have a pretty fluid local population, with many people living in border towns (Horn Lake, MS and West Memphis, AR) in Mississippi and Arkansas while working in Memphis. This tri-state kinship is signaled by Memphians ratings of these two state's speech as most similar to their own. But, this kinship does not seem to extend to their opinion of how correct and pleasant the speech spoken in these states is, which they rate significantly lower than speech spoken in Tennessee (Correctness: Compared to MS, $\mathrm{F}(1,182)=135.064, \mathrm{p}<.001$, and AR, $\mathrm{F}(1,182)=124.284, \mathrm{p}<.001$; Pleasantness: Compared to MS, $\mathrm{F}(1,181)=95.259$, $\mathrm{p}<.001$, and AR $\mathrm{F}(1,181)=95.161, \mathrm{p}<.001)$. This pattern of ratings seems contradictory- on one hand they find speech in Tennessee, Mississippi and Arkansas extremely similar, but, on the other hand, they separate the speech spoken in these areas by a large divide on correctness and pleasantness ratings. So why the split personality?

Memphians appear to recognize a 'core' South, one that roughly approximates an area often referred to as the 'deep' South. Owing to their adjacency to parts of MS and AR and the fact that many of the participants in this study have family from these surrounding areas, Memphians had a hard time separating themselves linguistically in terms of distance from that spoken across the border, but they seem to have little difficulty in separating themselves ideologically from the 'deep South', an area particularly tainted by offending stereotypes. All the negative images of the Southern states - rurality, poverty, racism - are often uttered about this area in particular, despite the prevalence of these problems in many other Southern states. The fact that Memphians are located so close to the heart of the devil itself may make the identification of differences more palpable and more necessary.

On the flip side, Memphians see the states that form the Eastern seaboard as faring much better in terms of relative regional correctness and pleasantness, a fact that may be partially related to their increased distance and unfamiliarity to Memphians. However, several other folk dialectology studies (Fought 2002, Niedzielski and Preston 2000) have also found these coastal states to be rated on par with other non-Southern regions in terms of correctness, suggesting that Memphians elevated view of this sub-region spawns from something greater than 


\section{Valerie Fridland}

sheer distance. One factor that may come into play is that the states on the Eastern seaboard have higher overall population and economic growth than other Southern States as reported in a study on the shifting patterns of Black migration in the U.S. (Fuguitt, Fulton, and Beale 2001). Also mentioned in that paper, this coastal area has had a greater net migration gain from the North and the West, perhaps leading to the perception of this area as being, like Florida and DC, affected by external (non-Southern) dialects. In addition, a sociology study (Shortridge 1987) found an increasing number of residents from this Southern coastal region identifying themselves not as residents of Southern states but of Eastern states. The author attributes this identity shift to greater affinity for the more liberal cultural values associated with the Eastern states rather than those traditionally associated with the South, prompted in part by increasing non-Southern migration into the coastal region. Although it may be doubtful that Memphians have direct access to such detailed population characteristics, their ratings elevation for this area is probably based on a relative lack of negative stereotypes for the South Atlantic states compared to those in the Mississippi River Delta along with their closer proximity to these, in their view, less prestigious state.

In conclusion, this research into the Southern psyche suggests that there is increasing dissatisfaction with an association with traditional definitions of Southern identity and this is reflected in part by Memphians tendency to separate themselves from other 'less' educated and pleasant areas of the South such as Alabama, Arkansas and Mississippi. Still, Memphians recognize themselves as part of the larger South, though this South now includes a number of states that are emerging with more positive images the farther away from traditional Southern stereotypes they are able to move. I believe what we are tapping into in such language attitude studies is a time of shift in the modern South, with locals in a state of redefinition in terms of what it means to be Southern. This reinvention of the Southern self-concept has the effect of fracturing the traditional relationship

among the Southern states, as some more successfully than others navigate the newly defined Southern seas.

\section{References}

Bookerrising.com. 2006. Fighting Stereotypes about Mississippi. http://bookerrising.blogspot.com/2006/12/fighting-stereotypes-aboutmississippi.html.

Fridland, Valerie. 2006. The Social and Linguistic Conditioning of Back Vowel Fronting Across Ethnic Groups in Memphis, TN. English Language and Linguistics 10: 1-22.

Fridland, Valerie. 2001. Social Factors in the Southern Shift: Gender, Age and Class. Journal of Sociolinguistics 5. 233-53. 


\section{Interpreting Intra-regional Southern Vowel Distinctions}

Fridland, Valerie, Bartlett, Kathryn and Roger Kreuz. 2005. Making Sense of Variation: Pleasantness and Education Ratings of Regional Vowel Variants. American Speech 80:366-387.

Fridland, Valerie, Bartlett, Kathryn and Roger Kreuz. 2004. Do You Hear What I Hear? Experimental Measurement of the Perceptual Salience of Acoustically Manipulated Vowel Variants by Southern Speakers in Memphis, TN. Language Variation and Change 16:1-16.

Fought, Carmen. 2002. California Students' Perceptions of, You Know, Regions and Dialects? In Dennis Preston and Daniel Long, eds. Handbook of Perceptual Dialectology, Volume 2. 113-134. Amsterdam: Benjamins.

Fuguitt, Glenn, John Fulton and Calvin Beale. 2001. The Shifting Pattern of Black Migration From and Into the Nonmetropolitan South, 1965-95. Economic Research Service/USDA Report No. ERSRDRR93.

Griffin, Larry and Ashley Thompson. 2003. Enough About the Disappearing South. What About the Disappearing Southerner. Southern Cultures. 51-64.

Labov, William. 1994. Principles of Linguistic Change: Internal Factors. Massachusetts: Blackwell.

Niedzielski, Nancy and Dennis Preston. 2000. Folklinguistics. New York: Mouton de Gruyter.

Preston, Dennis. 1986. Where the Worst English is Spoken. In Edgar W. Schneider, ed. Focus on the USA. 297-360. Amsterdam: Benjamins.

Preston, Dennis. 1989. Perceptual Dialectology. Dordrecht: Foris.

Preston, Dennis. 1993. Folk Dialectology. In Dennnis Preston, ed. American Dialect Research. 333-378. Englewood Cliffs, N.J.: Prentice Hall.

Reed, John Shelton, James Kohls and Carol Hanchette. 1990. The Dissolution of Dixie and the Changing Shape of the South. Social Forces. 321-378.

Shortridge, James (1987). Changing Usage of Four American Regional Labels. Annals of the Association of American Geographers 77:325-336.

U.S. Department of Commerce. 2001. 2000 Census of Population General Population Characteristics: Tennessee.

Valerie Fridland

Associate Professor

Department of English

Mailstop 0098

University of Nevada, Reno

Reno, NV 89557

fridland@unr.edu 